\title{
Licochalcone A, a natural chalconoid isolated from Glycyrrhiza inflata root, induces apoptosis via Sp1 and Sp1 regulatory proteins in oral squamous cell carcinoma
}

\author{
JUNG JAE CHO ${ }^{1 *}$, JUNG-IL CHAE ${ }^{2 *}$, GOO YOON $^{1}, \mathrm{KA} \mathrm{HWI} \mathrm{KIM}^{1}$, JIN HYOUNG CHO ${ }^{2}$, \\ SEUNG-SIK CHO ${ }^{1}$, YOUNG SIK CHO ${ }^{3}$ and JUNG-HYUN SHIM ${ }^{1}$
}

\author{
${ }^{1}$ Natural Medicine Research Institute, Department of Pharmacy, College of Pharmacy, Mokpo National University, \\ Jeonnam 534-729; ${ }^{2}$ Department of Oral Pharmacology, School of Dentistry and Institute of Oral Bioscience, \\ BK21 plus, Chonbuk National University, Jeonju 651-756; ${ }^{3}$ College of Pharmacy, \\ Keimyung University, Dalseo-gu, Daegu 704-701, Republic of Korea
}

Received March 5, 2014; Accepted May 7, 2014

DOI: 10.3892/ijo.2014.2461

\begin{abstract}
Licochalcone A (LCA), a chalconoid derived from root of Glycyrrhiza inflata, has been known to possess a wide range of biological functions such as antitumor, antiangiogenesis, antiparasitic, anti-oxidant, antibacterial and anti-inflammatory effects. However, the anticancer effects of LCA on oral squamous cell carcinoma (OSCC) have not been reported. Our data showed that LCA inhibited OSCC cell (HN22 and HSC4) growth in a concentration- and timedependent manner. Mechanistically, it was mediated via downregulation of specificity protein $1(\mathrm{Sp} 1)$ expression and subsequent regulation of Sp1 downstream proteins such as p27, p21, cyclin D1, Mcl-1 and survivin. Here, we found that LCA caused apoptotic cell death in HSC4 and HN22 cells, as characterized by sub- $\mathrm{G}_{1}$ population, nuclear condensation, Annexin V staining, and multi-caspase activity and apoptotic regulatory proteins such as $\mathrm{Bax}, \mathrm{Bid}, \mathrm{Bcl}_{\mathrm{xl}}$, caspase- 3 and PARP. Consequently, this study strongly suggests that LCA induces apoptotic cell death of OSCC cells via downregulation
\end{abstract}

Correspondence to: Dr Jung-Hyun Shim, Department of Pharmacy, College of Pharmacy, Mokpo National University, 1666 Youngsan-ro, Muan-gun, Jeonnam 534-729, Republic of Korea

E-mail: s1004jh@gmail.com

*Contributed equally

Abbreviations: OSCC, oral squamous cell carcinoma; LC, licochalcone; Sp1, specificity protein 1; DMEM, Dulbecco's modified Eagle's medium; FBS, fetal bovine serum; PBS, phosphate-buffered saline; Mcl-1, myeloid cell leukemia-1; PARP, poly(ADP-ribose) polymerase; P/S, penicillin and streptomycin; MTS, (3-(4,5-dimethylthiazol-2-yl)-5-(3-carboxymethoxyphenyl)-2-(4-sulfophenyl)2H-tetrazolium); DAPI, 4'-6-diamidino-2-phenylindole; PI, propidium iodide; LCE, licochalcone E; PI, propidium iodide

Key words: licochalcone A, apoptosis, specificity protein 1, oral squamous cell carcinoma of $\mathrm{Sp1}$ expression, prompting its potential use for the treatment of human OSCC.

\section{Introduction}

Oral cancers (subtype of head and neck cancer) have several types and are mostly $(\sim 90 \%)$ oral squamous cell carcinoma (OSCC) with complicated biological characteristics and clinical behavior (1). Commonly, the well-known risk factors of oral cancer are cigarettes, alcohol consuption, inflammation, mutation, preneoplasia, UV and HPV infection $(2,3)$. In spite of advanced cancer diagnosis, radiotherapy, chemotherapy and surgery, only slight improvement has been accomplished in the 5 -year survival rate of oral cancer patients over the last few decades (4). Although the visual screening of oral cavity is an easy examination of oral cancers, cancer lesions are not readily detected at the early stages (5). Because oral cancer is commonly diagnosed at late stage, the mortality rate from oral cancer is $\sim 50 \%$ (1). OSCC tends to metastasize or spread as soon as it forms, eventually leading to high mortality (6). Therefore, there is a demand for novel molecular targets for the management of oral cancers.

Recent studies reported that specificity protein $1(\mathrm{Spl}$ ) played a major role in the proliferation of tissues or organs as transcription factor and that it was also highly expressed in many cancer cells (7). Furthermore, it has been reported that the suppression of Spl protein in cancer cells is closely associated with growth regulation, cell cycle regulation, proliferation, biological response, differentiation, mortality and cell survival genes $(3,8)$. For the above reasons, the downregulation of $\mathrm{Spl}$ is increasingly attracting attention as a potential strategy for controlling oral cancer.

In spite of the efforts made to investigate many natural products to find effective chemicals for oral cancers over the last several decades (9), there are currently limited options to treat oral cancer. Even though the frequency of oral cancer is low, the need for effective and selective natural products is increasing. Licorice, the root and rhizome of several Glycyrrhiza species (Leguminosae), is an important natural sweetening agent and 
is widely used as a herbal medicine (3). Licochalcone A (LCA) is a novel flavonoid isolated from licorice root and is known to possess several bioactivities such as antioxidant, antibacterial, antiparasitic, anti-angiogenesis and antitumor effects (10-12). It reduces significantly $\mathrm{TNF}-\alpha$-induced $N F-\kappa \mathrm{B}$ activation, consequently resulting in decreased inflammatory cytokines production $(13,14)$. Additionally, LCA not only inhibits cancer cell proliferation, but also induces apoptosis in prostate and gastric cancer cells $(13,15,16)$. Consequently, LCA may be useful as an alternative compound for traditional anticancer agents.

In this study, therefore, we primarily examined the OSCC cell's response to LCA in order to determine the ability of the LCA to act as a chemotherapy agent. We concluded that LCA inhibits growth of OSCC cells (HN22 and HSC4) through induction of apoptotic cell death via suppression of $\mathrm{Spl}$ and its accompanying Sp1 regulatory proteins.

\section{Materials and methods}

LCA extraction and isolation. The roots of Glycyrrhiza inflata were purchased from Chonnam Herb Association (Hwasun, Korea). A voucher specimen (MNUYG-003) was deposited in the College of Pharmacy, Mokpo National University, Muan, Korea. The air-dried and powdered $G$. inflata roots $(600 \mathrm{~g})$ were extracted twice with $\mathrm{MeOH}$ (4 l) using sonicator for $3 \mathrm{~h}$. After filtration, the $\mathrm{MeOH}$ extracts were evaporated and suspended in distilled water and then defatted with $n$-hexane $(11)$. The aqueous layer was partitioned with methylene chloride $(3 \times 11)$. The evaporation residues $(5 \mathrm{~g})$ were subjected to flash silica gel chromatography eluting with $n$-hexane:EtOAc:MeOH (2:1:0.11:1:0.1-100\% $\mathrm{MeOH}$ ) to afford 10 fractions. Fractions 2, 3 and 4 were further subjected to flash silica gel chromatography, using a chloroform:MeOH (100:1) elution solution to get LCA (50 mg). LCA was finally purified by column chromatography using RP18 to an analytically acceptable purity.

Reagents and antibodies. Dulbecco's modified Eagle's medium (DMEM), fetal bovine serum (FBS), trypsin, penicillin and streptomycin (P/S) and phospate-buffered saline (PBS) were purchased (Thermo Scientific, Logan, UT, USA). Antibodies against Sp1, actin, caspase-3, p27, p21 and cyclin D1 were bought from Santa Cruz Biotechnology, Inc. (Santa Cruz, CA, USA). Antibodies that can recognize myeloid cell leukemia-1 (Mcl-1), survivin, Bid, Bax and $\mathrm{Bcl}_{-\mathrm{xl}}$ were from Cell Signaling (Danvers, MA, USA). A specific antibody for poly (ADP-ribose) polymerase (PARP) was obtained from BD Pharmingen (San Diego, CA, USA). A 4'-6-diamidino2-phenylindole (DAPI) was obtained from Sigma-Aldrich, Inc. (St. Louis, MO, USA).

Cell culture. HN22 and HSC4 cells were the human oral squamous cancer cell lines. HN22 cells and HSC4 cells were, respectively, provided by Dankook University (Cheonan, Korea) and Hokkaido University (Hokkaido, Japan). Both cells were cultured in DMEM containing $10 \%$ heat-inactivated FBS and $100 \mathrm{U} / \mathrm{ml}$ each of $\mathrm{P} / \mathrm{S}$ at $37^{\circ} \mathrm{C}$ with $5 \% \mathrm{CO}_{2}$ humidity.

3-(4,5-Dimethylthiazol-2-yl)-5-(3-carboxymethoxyphenyl)-2(4-sulfophenyl)-2H-tetrazolium (MTS) assay. Cell viability of
HN22 and HSC4 was determined using the CellTiter $96^{\circledR}$ AQueous One Solution Cell Proliferation Assay kit (Promega, Madison, WI, USA) according to the manufacturer's instructions. The cells were seeded in 96-well plates, grown for $24 \mathrm{~h}$ and treated with various concentrations of LCA. After treatment with LCA for 24 and $48 \mathrm{~h}$, MTS solution was added to each well and the plates were incubated for $2 \mathrm{~h}$ at $37^{\circ} \mathrm{C}$. Changes in absorbance were measured at $490 \mathrm{~nm}$ using an Enspire Multimode Plate reader (Perkin-Elmer, Akron, OH, USA).

DAPI staining. After treatment with LCA, the cells were harvested by trypsinization. The cells were washed with cold PBS and fixed in $100 \%$ methanol at room temperature for $20 \mathrm{~min}$. The cells were deposited on poly-L-lysine-coated slides, stained with DAPI solution $(2 \mu \mathrm{g} / \mathrm{ml})$ and observed through a FluoView confocal laser microscope (Flouview FV10i, Olympus Corp., Tokyo, Japan).

Cell cycle. HN22 $\left(5 \times 10^{5}\right)$ and HSC4 $\left(7.5 \times 10^{5}\right)$ cells were seeded and treated with LCA $(0,10,20$ and $40 \mu \mathrm{M})$ for $48 \mathrm{~h}$. The harvested cells were washed with $1 \mathrm{ml}$ PBS and $150 \mu \mathrm{l}$ of Muse $^{\mathrm{TM}}$ Cell cycle reagent (EMD Millipore Corp. Billerica, MA, USA) was added. Then, cells were incubated at RT for $30 \mathrm{~min}$ in the dark. Samples were measured with Muse Cell cycle kit (Merck Millipore, Billerica, MA, USA).

Reverse transcription-polymerase chain reaction (RT-PCR). To analyze the effect of LCA on OSCC cell lines (HN22 and HSC4), we performed RT-PCR using total RNAs and primers designed for the specific gene. Total RNAs were harvested from OSCC cells treated with or without LCA using the TRIzol ${ }^{\circledR}$ reagent (Life Technologies, Carlsbad, CA, USA). With $2.5 \mu \mathrm{g}$ of RNA, RT-PCR was done using HelixCript ${ }^{\mathrm{TM}}$ 1st-strand cDNA synthesis kit (NanoHelix, Korea) according to the kit instructions. We obtained cDNA using actin-specific and Sp1-specific primers under following PCR condition (30 cycles: $1 \mathrm{~min}$ at $95^{\circ} \mathrm{C}, 1 \mathrm{~min}$ at $56^{\circ} \mathrm{C}$ and $1 \mathrm{~min}$ at $72^{\circ} \mathrm{C}$ ). The actin primers used were as follows; forward: $5^{\prime}-\mathrm{GTG}$ GGG CGC CCC AGG CAC CA-3'; and reverse: 5'-CTC CTT AAT GTC ACG CAC GAT TTC-3'; and the Sp1 primers were; forward: 5'-ATG CCT AAT ATT CAG TAT CAA GTA-3'; and reverse: 5'-CCC TGA GGT GAC AGG CTG TGA-3'. Actin was used as an internal control. The RT-PCR products were visualized with ethidium bromide staining under UV light, after electrophoresis on a $2 \%$ agarose gel.

Western blotting. The lysates of treated cells were prepared using PRO-PREP ${ }^{\mathrm{TM}}$ Protein Extraction Solution (iNtRON Biotechnology, Korea) and then supernatants were removed by centrifugation. Proteins were separated by SDS-PAGE gel electrophoresis and transferred onto a polyvinylidenedifluoride (PVDF) membrane. After blocking with 5\% skim milk in PBST, the blots were incubated with primary antibody at $4^{\circ} \mathrm{C}$ overnight with mild shaking and then followed by its corresponding secondary antibody. The protein bands were visualized using ECL Plus Western Blotting Detection system (Santa Cruz Biotechnology).

Annexin V staining. HN22 $\left(5 \times 10^{5}\right)$ and HSC4 $\left(7.5 \times 10^{5}\right)$ cells were seeded and allowed to grow for $24 \mathrm{~h}$. At $48 \mathrm{~h}$ after 
A<smiles>C=CC(C)(C)c1cc(O)cc(/C=C/C(=O)c2ccc(O)cc2)c1</smiles>

Licochalcone A (LCA)

C

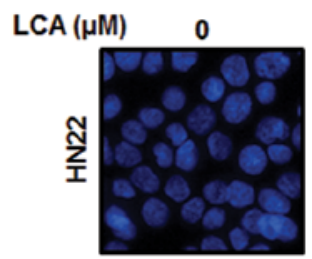

$\operatorname{LCA}(\mu \mathrm{M}) \quad 0$

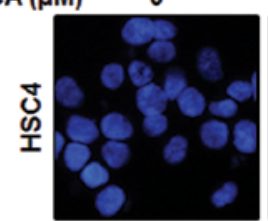

$B$

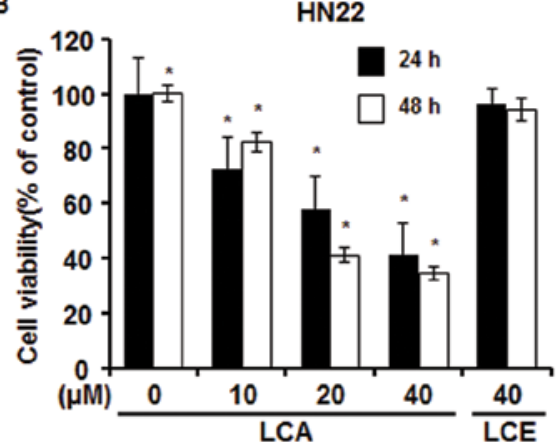

HSC4

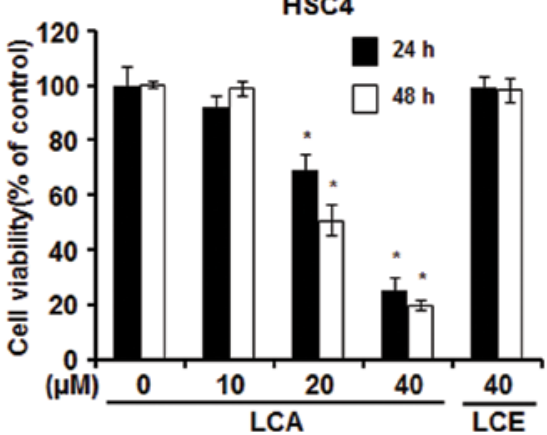

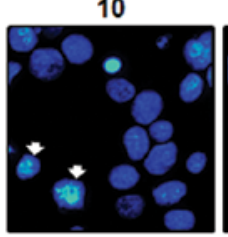

20
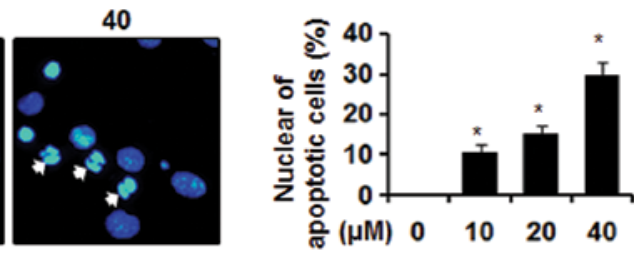

10
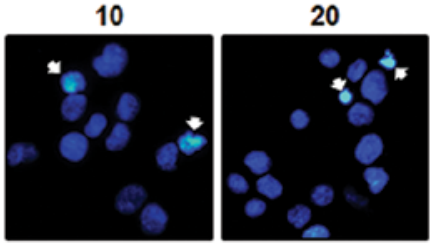

40
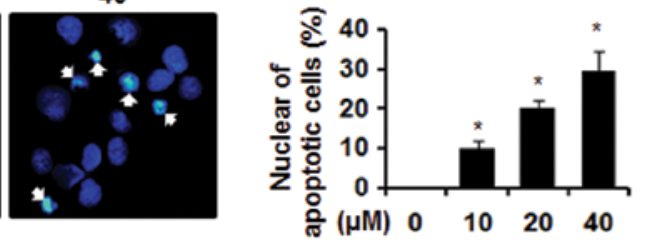

D
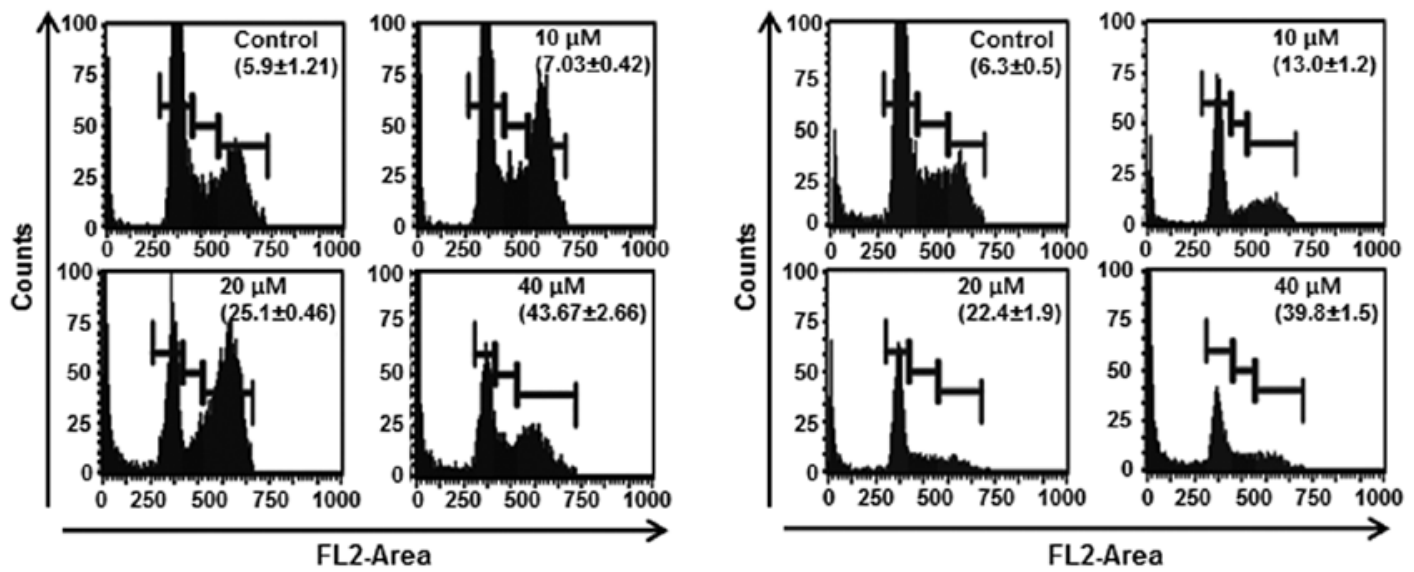

Figure 1. Effect of LCA on cell growth of oral squamous cell carcinoma (OSCC) cells. (A) Chemical structure of LCA. (B) Cell viability of HN22 and HSC4 exposed to LCA $(0,10,20$ and $40 \mu \mathrm{M})$ and LCE $(40 \mu \mathrm{M})$ for 24 and $48 \mathrm{~h}$. Cell viability was determined by MTS assay. (C) Fluorescence microscopic images of the DAPI-stained cells. The apoptotic cells, characterized by DNA fragmentation and nuclear condensation (white arrows), were counted and the data shown in the graph were expressed as means \pm SD of triplicate experiments. (D) Analysis of cell cycle was done $48 \mathrm{~h}$ after LCA treatment. The graph was representative of three independent experiments and the bar is the means \pm SD. ${ }^{*} p<0.05$ compared to untreated group.

treatment with various concentrations of LCA, cells were harvested by trypsinization and spinning down for analysis. The cells were analyzed by Muse Cell Analyzer with the Muse Annexin V \& Dead Cell kit (MCH100105, Merck Millipore). The whole process of analysis was performed following the instructions of the kit. The percentage of apoptotic and necrotic cells was calculated from each triplicate sample by statistical analysis of the dot plot using Muse 1.1.2 analysis software (Merck Millipore).

Multi-caspase assay. The process was carried out as instructed in the Muse Multi-Caspase kit (Merck Millipore). Each group, including negative and positive controls was harvested to measure quantitatively caspase activation and cell perme- ability. Cell samples in $1 \mathrm{X}$ caspase buffer with $50 \mu \mathrm{l}$ of Muse Multi-Caspase reagent working solution were incubated at $37^{\circ} \mathrm{C}$ for $30 \mathrm{~min}$. Then, $150 \mu \mathrm{l}$ of 7 -AAD working solution was added to each triplicate sample and samples were analyzed by Muse Cell Analyzer.

Statistical analysis. Using Student's t-test, the statistical significance was assessed. P-value at $<0.05$, was considered as statistically significant.

\section{Results}

LCA inhibits cell viability of OSCC. We investigated inhibitory effects of LCA (Fig. 1A) and LCE on cell proliferation 

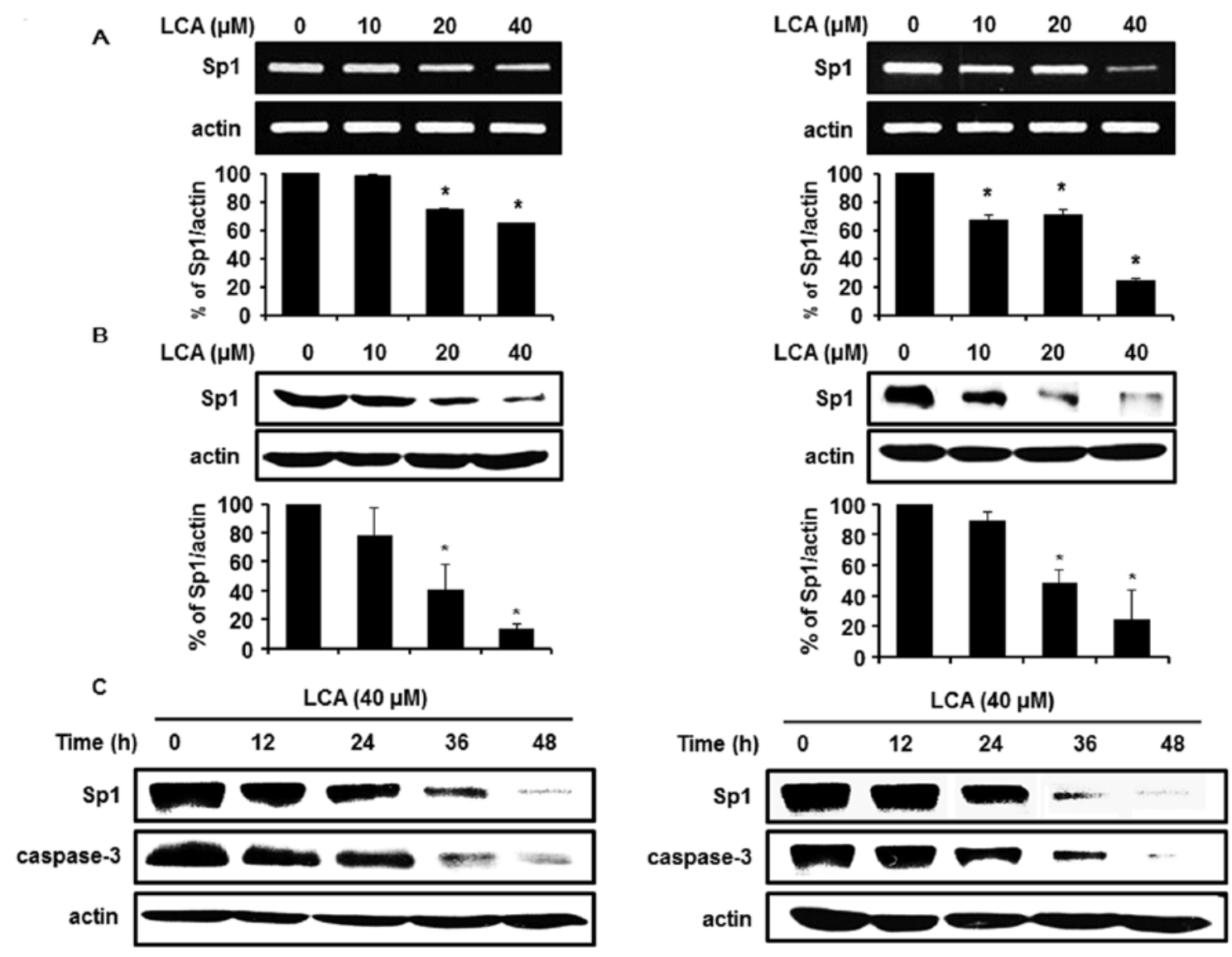

Figure 2. The effect of LCA on the expression of specificity protein 1 ( $\mathrm{Sp1}$ ) and apoptosis in HN22 and HSC4 cells. HN22 and HSC4 were treated with 10 , 20 and $40 \mu \mathrm{M}$ of LCA for $48 \mathrm{~h}$, and then the mRNA (A) and protein (B) levels of Sp1 were, respectively, detected by RT-PCR and western blot analysis. The graph indicates the relative ratio of Sp1 to actin. (C) To assess time-dependent effects of LCA on Sp1 and caspase-3, HN22 and HSC4 cells were exposed to $40 \mu \mathrm{M} \mathrm{LCA}$ for 12, 24, 36 and $48 \mathrm{~h}$ and then the resulting total proteins were immunoblotted with anti Sp1 and anti-caspase-3. Actin was used to normalize the protein loading from each group.

of OSCC. LCA and LCE were isolated from the extracts of licorice (Glycyrrhiza inflata) (17). Both have similar chemical structures but exert significantly different bioactivities (18). To examine the anticancer effects of LCA and LCE in OSCCs, the HN22 and HSC4 cells were treated with LCA or LCE at various concentrations for different times (24 and $48 \mathrm{~h}$ ). In this experiment, we used MTS assay to quantify cell viability after treatment with natural products. Fig. 1B showed that cell viability of HN22 and HSC4 was decreased in a dose- and time-dependent manner by LCA not LCE. The $\mathrm{IC}_{50}$ of LCA for cytotoxicity of HN22 and HSC4 post 48-h treatment was calculated as 17.87 and $20.42 \mu \mathrm{M}$, respectively. Specifically, cell viabilities of HN22 cells were, respectively, $82.4 \pm 3.4$, $41.2 \pm 2.7$ and $34.4 \pm 2.1 \%$ of the control group at 10,20 and $40 \mu \mathrm{M}$ of LCA $48 \mathrm{~h}$ after treatment. HSC4 had a similar doseresponse relationship to $\mathrm{HN} 22$, representing $98.6 \pm 2.5,50.7 \pm 5.4$ and $19.6 \pm 1.7 \%$ viability at 10,20 and $40 \mu \mathrm{M}$, respectively.

LCA induces apoptosis in OSCCs. Generally, the proliferation of cancer cells can be suppressed by apoptosis or induction of cell cycle arrest, or both $(9,19)$. To investigate if LCA would induce apoptosis of HN22 and HSC4 cells, DAPI staining, sub- $\mathrm{G}_{1}$ cell cycle analysis and Annexin $\mathrm{V}$ staining were conducted. As shown in Fig. 1C, we found that LCA induced apoptosis of OSCC cells in dose-dependent manner, as deter- mined by fragmentation and condensation of DNA. The cell cycle distribution was analyzed after PI staining by Muse Cell Analyzer. The treatment of cells with LCA at a dose of $40 \mu \mathrm{M}$ caused $\sim 43.67 \pm 2.66$ or $39.8 \pm 1.5 \%$ induction of sub $-\mathrm{G}_{1}$ cell population in HN22 (Fig. 1D, left) and HSC4 (Fig. 1D, right), respectively. We quantified apoptotic cells by flow cytometric analysis of cells with Annexin V/7-AAD double staining. Exposure of HN22 cells to LCA for $48 \mathrm{~h}$ resulted in an increase in the late-apoptotic cell population (Fig. 5A, upper right quadrant) from 9.45 to $87.33 \%$ with LCA 10 and $40 \mu \mathrm{M}$, respectively, compared with $0.78 \%$ of control cells. In HSC 4 cells, the percentage of late-apoptotic cells increased from $2.86 \%$ in control cells to $26.46 \%$ after $40 \mu \mathrm{M}$ treatment with LCA, respectively (Fig. 5B).

LCA suppresses Sp1 expression in OSCC. $\mathrm{Sp1}$ protein plays an important role in cell cycle progression, oncogenesis and apoptotic cell death through modulation of target gene promoters (20-22). According to our previous report, $\mathrm{Sp1}$ is an essential transcription factor for OSCC tumorigenesis (23). Therefore, we reasoned that $\mathrm{Sp} 1$ protein might be a target for regulating growth of OSCC. To verify the correlation of Sp1 expression to apoptosis, Sp1 expression levels were monitored after cells were exposed to increasing doses of LCA for given times. LCA significantly downregulated the Sp1 mRNA and 
A

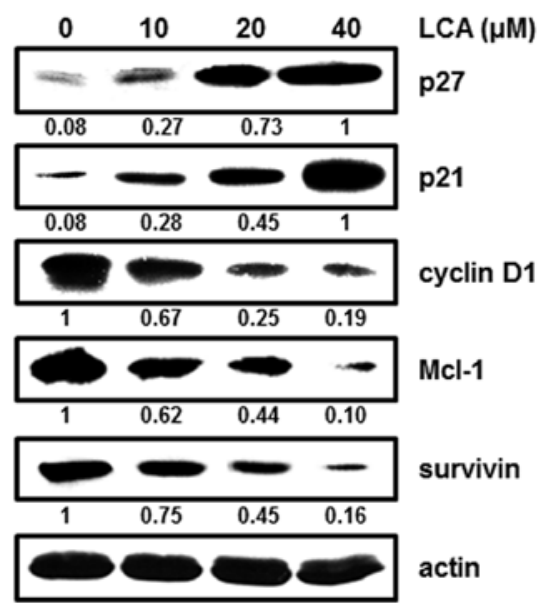

B

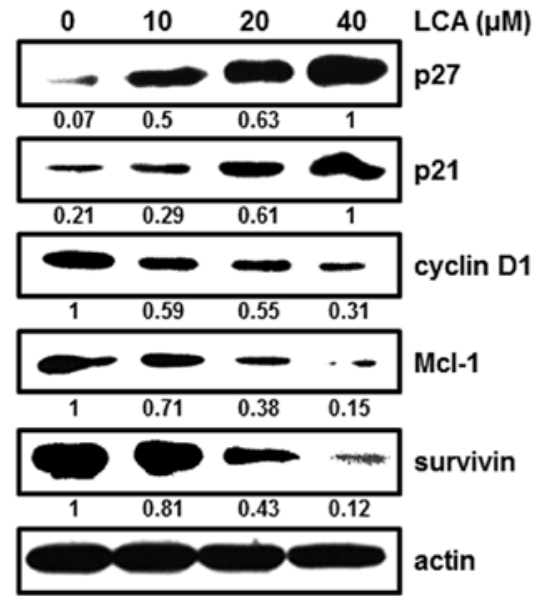

Figure 3. The effects of LCA on the downstream target proteins of Sp1. HN22 (A) and HSC4 (B) cells were treated with 10, 20 and $40 \mu \mathrm{M}$ of LCA for $48 \mathrm{~h}$. The protein expression of p27, p21, cyclin D1, Mcl-1 and survivin was investigated by western blots. The values below the western blot band indicate relative average density to actin.

A

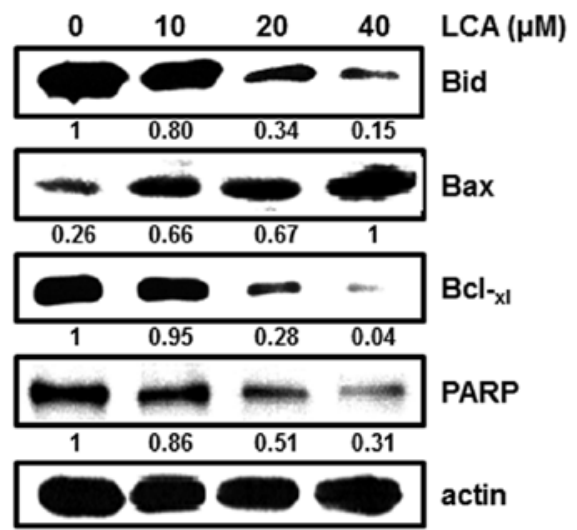

B

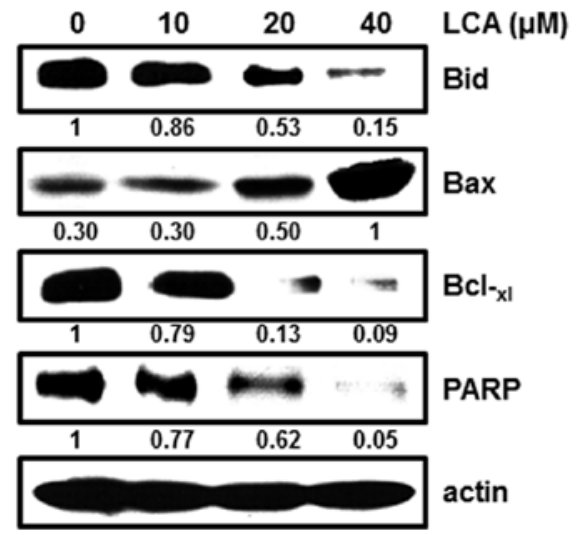

Figure 4. Apoptotic cell death and expression of proteins associated with apoptosis in OSCC treated with LCA. OSCC cells of HN22 (A) and HSC4 (B) were treated with 10, 20 and $40 \mu \mathrm{M}$ of LCA for $48 \mathrm{~h}$. The cell lysate were determined by western blot analysis using antibodies against Bid, Bax, Bcl- ${ }_{x \mathrm{xl}}$, poly (ADP-ribose) polymerase (PARP), respectively. Actin was detected to confirm equal loading.

protein expression levels in a dose-dependent manner in the HN22 and HSC4 cells (Fig. 2A and B). We also compared amounts of Sp1 and caspase-3 in HN22 and HSC4 cells treated with $40 \mu \mathrm{M}$ LCA for various times $(0,12,24,36$ and $48 \mathrm{~h})$. The levels of both Sp1 protein and caspase-3 were gradually decreased with times by LCA. The Sp1 protein governs the downstream targets including p27, p21, cyclin D1, Mcl-1 and survivin, dysregulated expression of which causes apoptosis and cell cycle arrest in various cancer cells $(20,23)$. Cell cycle arrest proteins such as p27 and p21 were elevated in HN22 (Fig. 3A) and HSC4 (Fig. 3B) by LCA treatment while cell proliferation and survival-related proteins like cyclin D1, Mcl-1 and survivin were diminished (Fig. 3B) in a dose-dependent manner by LCA.

LCA modulates the factors related to apoptosis of OSCC cells. It has been reported in many previous studies that the downregulation of $\mathrm{Sp} 1$ is associated with apoptosis induction
(24-26). To clarify the link between LCA and Sp1-mediated apoptosis, we carried out western blot analysis of apoptosisregulating proteins with respective specific antibody in LCA-treated OSCC cells (Fig. 4). Consequently, as anticipated, a decrease in Bid and $\mathrm{Bcl}_{\mathrm{xl}}$ expression and an increase in Bax were observed in cells treated with LCA. It is well established that fluctuation in levels of those proteins is related to apoptotic cell death. Finally, the cleavage of PARP was enhanced in a dose-dependent manner by LCA treatment. As shown in Fig. 5C and D, OSCC cells exposed to LCA showed increase of multi-caspase activity in a dose-dependent manner. The multi-caspase acitivity of HN22 was (Fig. 5C), respectively, $10.11 \pm 1.69,8.44 \pm 3.94$ and $15.87 \pm 1.11 \%$ of early to mid apoptotic cells and $15.36 \pm 0.2,22.91 \pm 0.61$ and $50.97 \pm 1.0 \%$ of late apoptotic/dying cells at 10,20 and $40 \mu \mathrm{M}$ of LCA compared with the untreated control cells when multi-caspase activity was calculated at $48 \mathrm{~h}$ post-treatment. In the case of HSC4 (Fig. 5D), multi-caspase activity was $6.75 \pm 0.83,10.37 \pm 0.70$ 
A

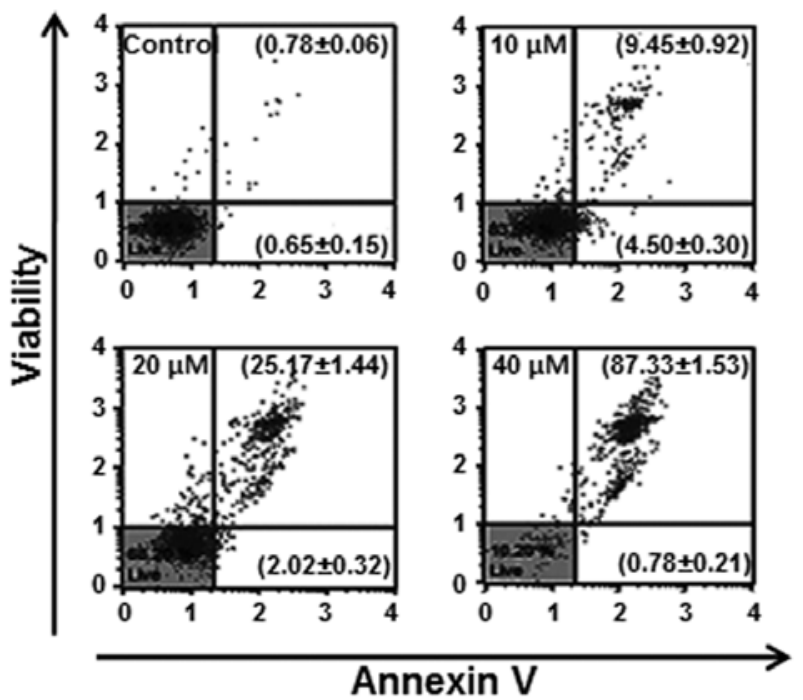

C

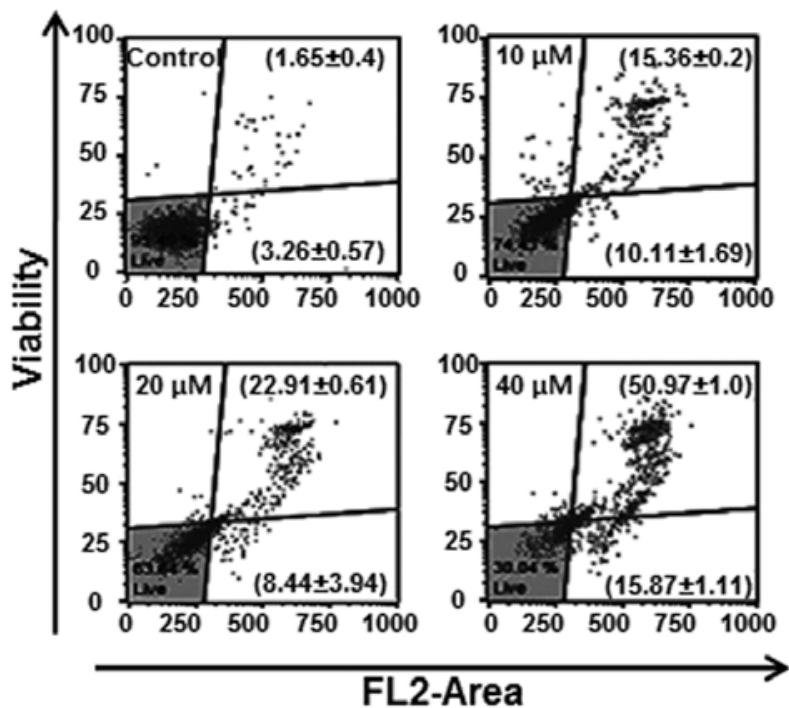

B
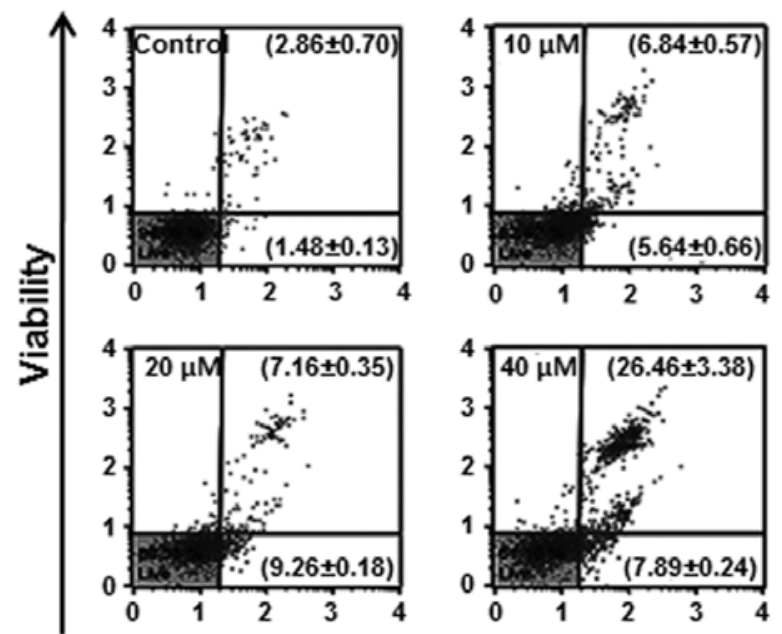

Annexin V

D

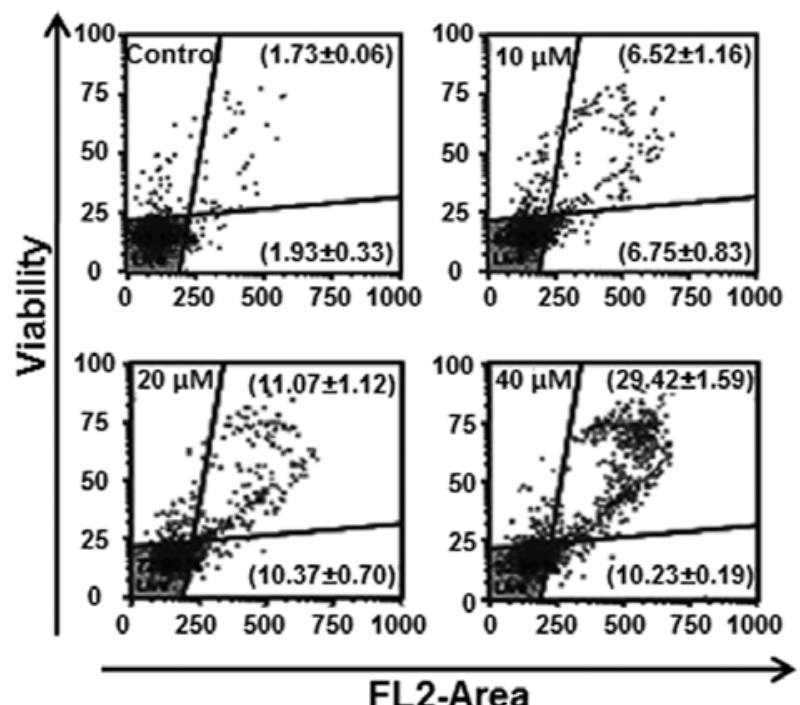

Figure 5. Flow cytometric analysis of OSCC cells treated with LCA. HN22 (A and C) and HSC4 (B and D) were treated with various concentrations of LCA for $48 \mathrm{~h}$ and then apoptotic cells were examined with Muse Cell Analyzer after Annexin V and multi-caspase staining. (A and B) Muse Cell Analyzer profile represents Annexin V staining in x-axis and viability of staining in y-axis. The number represents the percentage of early to mid apoptotic cells (lower right quadrant) and late apoptotic/dying cells (upper right quadrant) in each condition. (C and D) Muse Cell Analyzer profile indicates multi-caspase staining in $\mathrm{x}$-axis and viability of staining in $\mathrm{y}$-axis. The numbers represent the percentage of caspase positive cells (lower right quadrant) and caspase positive cells/dying cells (upper right quadrant) in each experimental group. The data are expressed as the mean \pm SD of three experiments in triplicates.

and $10.23 \pm 0.19 \%$ of early to mid apoptotic cells and $6.52 \pm 1.16$, $11.07 \pm 1.12$ and $29.42 \pm 1.59 \%$ of late apoptotic/dying cells at 10 , 20 and $40 \mu \mathrm{M}$ of LCA, respectively. We conclude that downregulation of Sp1 by LCA leads to apoptotic cell death.

\section{Discussion}

Licorice has been extensively studied because it is an important natural sweetening agent and widely used as a herbal medicine. Recent studies have reported that LCA and LCE, retrochalcones derived from root of Glycyrrhiza inflata, reduces inflammation, migration, angiogenesis, tumorigenesis, is antidiabetic, inducing cell cycle arrest and apoptosis in various cancer cell lines both in vitro and in vivo $(10,16,27)$. LCA has been reported to induce bladder cancer apoptosis via modulation of mitochondria dysfunction and endoplasmic reticulum stress (12). Additionally, LCA suppresses the migration and invasion of hepatomacellular cell carcinoma (HCC) by reducing MKK4/JNK via NF- $\kappa \mathrm{B}$-mediated urokinase plasminogen activator (uPA) expression (10). LCE was found not only to induce adipocyte differentiation during adipogenesis, but also to have antidiabetic activity in diabetic mice (27).

Oral squamous cell carcinoma (OSCC) is an aggressive epithelial malignancy and has a poor prognosis despite comprehensive understanding of cancer development and advanced therapy. There is accumulating evidence that LCA and LCE exert an antitumor effect against a variety of cancers, but neither has been investigated in OSCC to our knowledge. Therefore, we first sought to check the biological 
effects of LCA and LCE on OSCC cell lines (HN22 and HSC4). In this study, LCA effectively inhibited cell growth and induced apoptosis so that if could be a suitable candidate for inhibiting cell growth and inducing apoptosis in OSCC cells, whereas LCE was not effective in these cell lines. Although LCA and LCE share very similar structures, they exerted different biological effects in OSCC cells with respect to cell growth and death.

The transcription factor $\mathrm{Sp} 1$ is known to be ubiquitously overexpressed in various human cancer cells and closely associated with tumor activity by cellular processes (28-30). Many studies have already revealed the relationship between upregulated $\mathrm{Sp} 1$ and biological processes such as proliferation, differentiation and oncogenesis $(31,32)$. Therefore, $\mathrm{Sp} 1$ has been suggested as a promising target for molecular therapy against oral cancer. In this study, treatment of OSCC cells (HN22 and HSC4) with LCA decreased significantly expression of $\mathrm{Sp} 1$ protein in a dose- and time-dependent manner. To further strengthen the effect of LCA on Sp1, we scrutinized expression of Sp1 target proteins such as p21, p27, cyclin D1, Mcl-1 and survivin $(9,33,34)$. The promoter of $\mathrm{Sp} 1$ target proteins contains frequent GC-rich sequences and can be regulated by Sp1 protein (35-37). Both $\mathrm{p} 21$ and $\mathrm{p} 27$, regulators of cell cycle progression $(38,39)$, were dose-dependently increased when treated with LCA. The proto-oncogene cyclin D1 governs $\mathrm{G}_{1}$ to $\mathrm{S}$ phase progression and is accordingly involved in the development and progression of various cancers $(40,41)$. The member of the Bcl-2 family Mcl-1 regulates mitochondrial physiology, energy production and anti-apoptotic function $(35,42)$. It also plays an important role in promoting carcinogenesis $(42,43)$. The pro-survival protein survivin is an apoptosis inhibitor and a key regulator of mitosis, closely associated with carcinogenesis (44). Consistent with its role, it was demonstrated to be upregulated in many human cancer cells (45). Therefore, cyclin D1, survivin and Mcl-1 in cancer cells have emerged as potential therapeutic targets. Following LCA treatment, downregulation of both $\mathrm{Sp} 1$ and $\mathrm{Sp1}$ regulatory proteins (cyclin D1, survivin and Mcl-1) was observed. Accordingly, it can be summarized that LCA activated apoptotic signaling pathways in OSCC through regulation of Sp1 and ensuing Sp1 target proteins. Apoptotic cell death is subclassified by intrinsic mitochondria-mediated pathway and extrinsic death receptorinduced pathway. In an intrinsic pathway, mitochondrial events such as reciprocal expression of anti-apoptotic protein $\mathrm{Bcl}-2$, $\mathrm{Bcl}_{\mathrm{xl}}$ and pro-apoptotic protein $\mathrm{Bax}$ are the prerequisite for the activation of caspases. Consistent with this, LCA substantially reduced Bid and $\mathrm{Bcl}_{\mathrm{xl}}$ expression, but elevated Bax expression. Subsequently, a cascade of molecular apoptotic signaling transduction occurred for LCA-mediated apoptosis.

In conclusion, our results indicate that LCA mediates its anti-proliferative and apoptotic effects through suppression of Sp1 and Sp1-mediated signaling pathways. Our study strongly suggests that LCA is promising for treatment of OSCC that overexpresses $\mathrm{Sp} 1$ through $\mathrm{Sp} 1$ regulation and that it is further applicable as an anticancer drug and/or a conjunction agent.

\section{Acknowledgements}

This study was supported by Basic Science Research Program through the National Research Foundation Korea (NRF) funded by the Ministry of Education, Science and Technology (2013R1A1A2A10057695).

\section{References}

1. Oliveira LR, Castilho-Fernandes A, Oliveira-Costa JP, et al: CD $44^{+} / \mathrm{CD}_{133^{+}}$immunophenotype and matrix metalloproteinase-9 influences on prognosis of early stage oral squamous cell carcinoma patients. Head Neck: Nov 1, 2013 (Epub ahead of print). doi: 10.1002/hed.23527.

2. Tanaka T, Tanaka M and Tanaka T: Oral carcinogenesis and oral cancer chemoprevention: a review. Pathol Res Int 2011: 431246, 2011.

3. Yu HJ, Shin JA, Nam JS, et al: Apoptotic effect of dibenzylideneacetone on oral cancer cells via modulation of specificity protein 1 and Bax. Oral Dis 19: 767-774, 2012.

4. Choi ES, Cho SD, Jeon JG, et al: The apoptotic effect of the hexane extract of Rheum undulatum L. in oral cancer cells through the down-regulation of specificity protein 1 and survivin. Lab Anim Res 27: 19-24, 2011.

5. Ariyawardana A and Ekanayake L: Screening for oral cancer/ pre-cancer: knowledge and opinions of dentists employed in the public sector dental services of Sri Lanka. Asian Pac J Cancer Prev 9: 615-618, 2008.

6. Yeole BB, Ramanakumar AV and Sankaranarayanan R: Survival from oral cancer in Mumbai (Bombay), India. Cancer Causes Control 14: 945-952, 2003.

7. Lee HE, Choi ES, Shin JA, et al: Apoptotic effect of methanol extract of Picrasma quassioides by regulating specificity protein 1 in human cervical cancer cells. Cell Biochem Funct 32: 229-235 2014.

8. Firestone GL and Bjeldanes LF: Indole-3-carbinol and 3-3'-diindolylmethane antiproliferative signaling pathways control cell-cycle gene transcription in human breast cancer cells by regulating promoter-Sp1 transcription factor interactions. J Nutr 133: S2448-S2455, 2003.

9. Jeon YJ, Ko SM, Cho JH, et al: The HDAC inhibitor, panobinostat, induces apoptosis by suppressing the expresssion of specificity protein 1 in oral squamous cell carcinoma. Int $\mathbf{J}$ Mol Med 32: 860-866, 2013.

10. Tsai JP, Hsiao PC, Yang SF, et al: Licochalcone A suppresses migration and invasion of human hepatocellular carcinoma cells through downregulation of MKK4/JNK via NF- $\mathrm{KB}$ mediated urokinase plasminogen activator expression. PloS One 9: e86537, 2014.

11. Hao H, Hui W, Liu P, et al: Effect of licochalcone A on growth and properties of Streptococcus suis. PloS One 8: e67728, 2013.

12. Yuan X, Li D, Zhao H, et al: Licochalcone A-induced human bladder cancer T24 cell apoptosis triggered by mitochondria dysfunction and endoplasmic reticulum stress. Biomed Res Int 2013: 474272, 2013.

13. Lee CS, Kwak SW, Kim YJ, et al: Guanylate cyclase activator YC-1 potentiates apoptotic effect of licochalcone A on human epithelial ovarian carcinoma cells via activation of death receptor and mitochondrial pathways. Eur J Pharmacol 683: 54-62, 2012.

14. Funakoshi-Tago M, Tanabe S, Tago K, et al: Licochalcone A potently inhibits tumor necrosis factor alpha-induced nuclear factor-kappaB activation through the direct inhibition of IkappaB kinase complex activation. Mol Pharmacol 76: 745-753, 2009.

15. Fu Y, Hsieh TC, Guo J, et al: Licochalcone-A, a novel flavonoid isolated from licorice root (Glycyrrhiza glabra), causes G2 and late-G1 arrests in androgen-independent PC-3 prostate cancer cells. Biochem Biophys Res Commun 322: 263-270, 2004.

16. Xiao XY, Hao M, Yang XY, et al: Licochalcone A inhibits growth of gastric cancer cells by arresting cell cycle progression and inducing apoptosis. Cancer Lett 302: 69-75, 2011.

17. Yoon G, Jung YD and Cheon SH: Cytotoxic allyl retrochalcone from the roots of Glycyrrhiza inflata. Chem Pharm Bull 53: 694-695, 2005.

18. Fu Y, Chen J, Li YJ, et al: Antioxidant and anti-inflammatory activities of six flavonoids separated from licorice. Food Chem 141: 1063-1071, 2013.

19. Chang SF, Chang CA, Lee DY, et al: Tumor cell cycle arrest induced by shear stress: Roles of integrins and Smad. Proc Natl Acad Sci USA 105: 3927-3932, 2008.

20. Lee KA, Lee SH, Lee YJ, et al: Hesperidin induces apoptosis by inhibiting Sp1 and its regulatory protein in MSTO-211H cells. Biomol Ther 20: 273-279, 2012. 
21. Li L and Davie JR: The role of Sp1 and Sp3 in normal and cancer cell biology. Ann Anat 192: 275-283, 2010.

22. Willoughby JA Sr, Sundar SN, Cheung M, et al: Artemisinin blocks prostate cancer growth and cell cycle progression by disrupting Sp1 interactions with the cyclin-dependent kinase-4 (CDK4) promoter and inhibiting CDK4 gene expression. J Biol Chem 284: 2203-2213, 2009.

23. Kim DW, Ko SM, Jeon YJ, et al: Anti-proliferative effect of honokiol in oral squamous cancer through the regulation of specificity protein 1. Int J Oncol 43: 1103-1110, 2013.

24. Deniaud E, Baguet J, Mathieu AL, et al: Overexpression of Sp1 transcription factor induces apoptosis. Oncogene 25: 7096-7105, 2006.

25. Jutooru I, Chadalapaka G, Sreevalsan S, et al: Arsenic trioxide downregulates specificity protein $(\mathrm{Sp})$ transcription factors and inhibits bladder cancer cell and tumor growth. Exp Cell Res 316: 2174-2188, 2010

26. Shin JA, Kim JJ, Choi ES, et al: In vitro apoptotic effects of methanol extracts of Dianthus chinensis and Acalypha australis L. targeting specificity protein 1 in human oral cancer cells. Head Neck 35: 992-998, 2012.

27. Park HG, Bak EJ, Woo GH, et al: Licochalcone E has an antidiabetic effect. J Nutr Biochem 23: 759-767, 2012.

28. Chiefari E, Brunetti A, Arturi F, et al: Increased expression of AP2 and Sp1 transcription factors in human thyroid tumors: a role in NIS expression regulation? BMC Cancer 2: 35, 2002.

29. Hosoi Y, Watanabe T, Nakagawa K, et al: Upregulation of DNA-dependent protein kinase activity and $\mathrm{Spl}$ in colorectal cancer. Int J Oncol 25: 461-468, 2004.

30. Yao JC, Wang L, Wei D, et al: Association between expression of transcription factor Sp1 and increased vascular endothelial growth factor expression, advanced stage, and poor survival in patients with resected gastric cancer. Clin Cancer Res 10: 4109-4117, 2004

31. Chu S and Ferro TJ: Sp1: regulation of gene expression by phosphorylation. Gene 348: 1-11, 2005.

32. Deniaud E, Baguet J, Chalard R, et al: Overexpression of transcription factor $\mathrm{Spl}$ leads to gene expression perturbations and cell cycle inhibition. PLoS One 4: e7035, 2009.

33. Blume SW, Snyder RC, Ray R, et al: Mithramycin inhibits SP1 binding and selectively inhibits transcriptional activity of the dihydrofolate reductase gene in vitro and in vivo. J Clin Invest 88: 1613-1621, 1991
34. Pietrzak $\mathrm{M}$ and Puzianowska-Kuznicka M: p53-dependent repression of the human MCL-1 gene encoding an anti-apoptotic member of the BCL-2 family: the role of Spl and of basic transcription factor binding sites in the MCL-1 promoter. Biol Chem 389: 383-393, 2008.

35. Choi KH, Shim JH, Huong LD, et al: Inhibition of myeloid cell leukemia-1 by tolfenamic acid induces apoptosis in mucoepidermoid carcinoma. Oral Dis 17: 469-475, 2011.

36. Li F and Altieri DC: Transcriptional analysis of human survivin gene expression. Biochem J 344 Pt 2: 305-311, 1999.

37. Li Y, Xie M, Yang J, et al: The expression of antiapoptotic protein survivin is transcriptionally upregulated by DEC1 primarily through multiple sp1 binding sites in the proximal promoter. Oncogene 25: 3296-3306, 2006.

38. Sherr CJ and Roberts JM: CDK inhibitors: positive and negative regulators of G1-phase progression. Genes Dev 13: 1501-1512, 1999.

39. Murray AW: Recycling the cell cycle: cyclins revisited. Cell 116: 221-234, 2004.

40. Weinstein IB: Relevance of cyclin D1 and other molecular markers to cancer chemoprevention. J Cell Biochem (Suppl) 25: 23-28, 1996.

41. Alao JP: The regulation of cyclin D1 degradation: roles in cancer development and the potential for therapeutic invention. Mol Cancer 6: 24, 2007.

42. Akgul C: Mcl-1 is a potential therapeutic target in multiple types of cancer. Cell Mol Life Sci 66: 1326-1336, 2009.

43. Andersson Y, Juell S and Fodstad O: Downregulation of the antiapoptotic MCL-1 protein and apoptosis in MA-11 breast cancer cells induced by an anti-epidermal growth factor receptor - Pseudomonas exotoxin a immunotoxin. Int J Cancer 112: 475-483, 2004.

44. Chun JY, Hu Y, Pinder E, et al: Selenium inhibition of survivin expression by preventing Sp1 binding to its promoter. Mol Cancer Ther 6: 2572-2580, 2007.

45. Sun Y, Giacalone NJ and Lu B: Terameprocol (tetra-O-methyl nordihydroguaiaretic acid), an inhibitor of Sp1-mediated survivin transcription, induces radiosensitization in non-small cell lung carcinoma. J Thorac Oncol 6: 8-14, 2011. 